\title{
Validation of a T1 and T2 mapping software for quantitative MRI
}

\author{
Sebastian Bidhult ${ }^{1,2^{*}}$, Georgios Kantasis ${ }^{1,3}$, Anthony H Aletras ${ }^{1,3}$, Einar Heiberg ${ }^{1,2}$ \\ From 19th Annual SCMR Scientific Sessions \\ Los Angeles, CA, USA. 27-30 January 2016
}

\section{Background}

T1 quantification enables measurements of myocardial extracellular volume [1] and T2 mapping may be used for detection of edema in acute myocardial infarction [2]. The purpose of this study was to develop and validate a freely available software for relaxation time map generation.

\section{Methods}

The T1 \& T2 mapping modules were implemented in Segment [3] and support the pulse sequence types shown in Table 1. T1 estimates were initialized by a lookup table search in an interval of 0-4000 ms and a 5 ms gap between entries. T2 estimates were initialized by linear regression to the signal logarithm. Relaxation time estimates were refined using a C-implementation of the Nelder-Mead Simplex method. Twelve Gadolinium-Agarose phantoms were used for validation at a $1.5 \mathrm{~T}$ and a $3 \mathrm{~T}$ MR-scanner (Siemens, Erlangen). Reference $\mathrm{T} 1$ values were determined using an Inversion Recovery (IR) Spin Echo sequence with TR $=10$ seconds. Reference T2 values were determined using a Spin Echo sequence with TR $=10$ seconds. Nelder-Mead Simplex optimization available in Matlab (Math Works, Natick, MA; 2013a) was used for reference relaxation time values.

The proposed modules generated relaxation time maps from two free-breathing, single-shot bSSFP sequences. Saturation-Recovery (SR) and T2-preparation prepulses were used to create T1 \& T2 weighting. Apart from T2-prepared images, a saturation prepared image was used in the T2 estimates, as previously proposed [4]. In addition, T1 was estimated with MOLLI at $1.5 \mathrm{~T}$ using 5(3b)3 and 4(1b)3(1b) 2 schemes. Acquisition times for the three bSSFP sequences were $13 \mathrm{~min} 15 \mathrm{sec}$

'Department of Clinical physiology, Skåne University Hospital in Lund, Lund Cardiac MR Group, Lund, Sweden

Full list of author information is available at the end of the article for T1-SR, $11 \mathrm{sec}$ for T1-MOLLI and $14 \mathrm{~min} 3 \mathrm{sec}$ for the T2 sequence. Bias and Variability were determined using modified Bland-Altman analysis. Error percentages were computed by dividing the difference between the evaluated method and the reference with the reference value.

\section{Results}

$\mathrm{T} 1$ and T2 reference values ranged from $214-1690 \mathrm{~ms}$ and 46-190 ms, respectively. Figure 1 shows the phantom validation results at $1.5 \mathrm{~T}$. Bias and variability (limits of agreement) at $1.5 \mathrm{~T}$ were $-0.32 \pm 1.31 \%$ for SR-bSSFP and $-4.96 \pm 5.53 \%$ for MOLLI. MOLLI data with errors $>6 \%$ originated from phantoms with reference T2 values $<60 \mathrm{~ms}$. Bias and variability at $3 \mathrm{~T}$ were $-2.15 \pm$ $2.66 \%$ (SR-bSSFP). T2 bias and variability were $1.95 \pm$ $4.06 \%$ at $1.5 \mathrm{~T}$ and $0.37 \pm 5.06 \%$ at $3 \mathrm{~T}$.

\section{Conclusions}

A T1 \& T2 mapping software was developed and evaluated. Low bias and variability was found for the T1-SR sequence. The increased variability of MOLLI compared to the SR sequence may be explained by the reduced number of sampling points used in MOLLI and an increasing $\mathrm{T} 1$ error for low $\mathrm{T} 2$ values. The increased variability of the T2-prepared sequence may be explained by limited SNR.

\section{Authors' details \\ ${ }^{1}$ Department of Clinical physiology, Skåne University Hospital in Lund, Lund Cardiac MR Group, Lund, Sweden. 'Faculty of Engineering, Lund University, Department of Biomedical Engineering, Lund, Sweden. ${ }^{3}$ School of Medicine, Aristotle University of Thessaloniki, Laboratory of Medical Informatics, \\ Thessaloniki, Greece.}

Published: 27 January 2016 
T1-SR bSSFP at 1.5T: Error Percentage

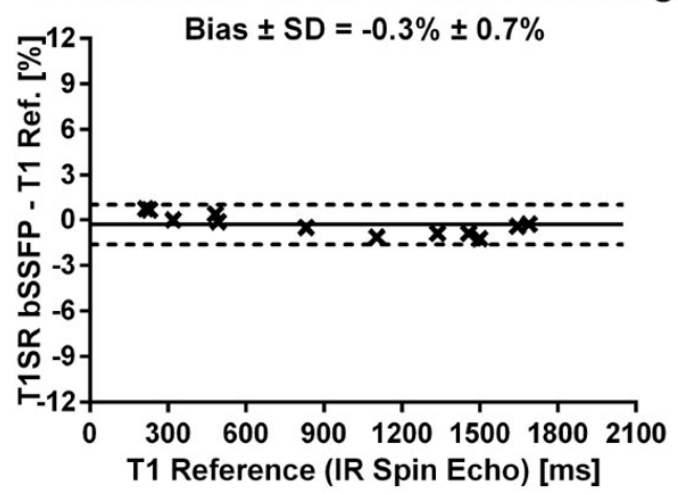

T2-Prepared bSSFP at 1.5T: Error Percentage

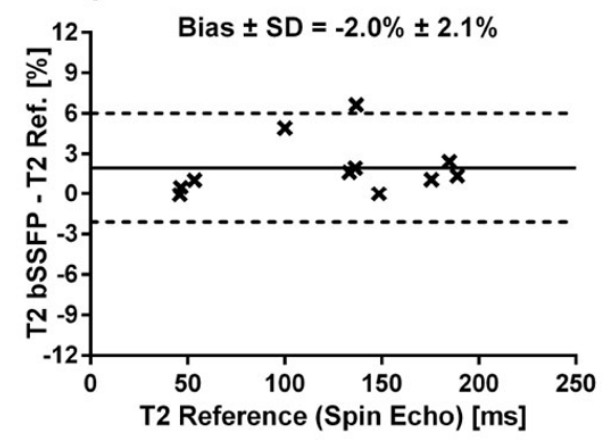

T1-MOLLI at 1.5T: Error Percentage

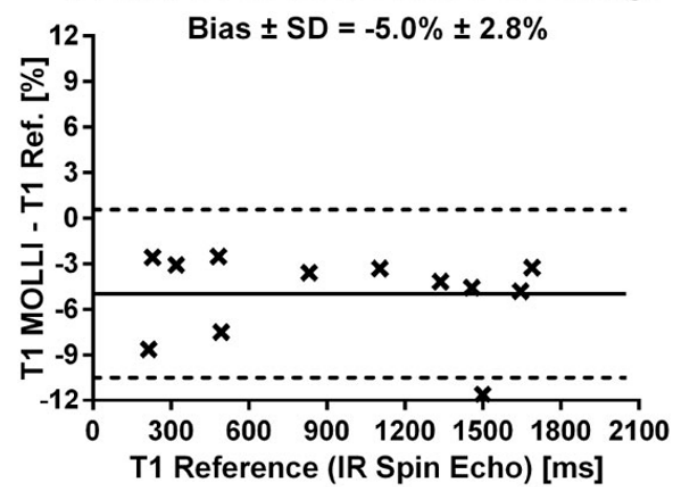

T1-SR bSSFP example fit

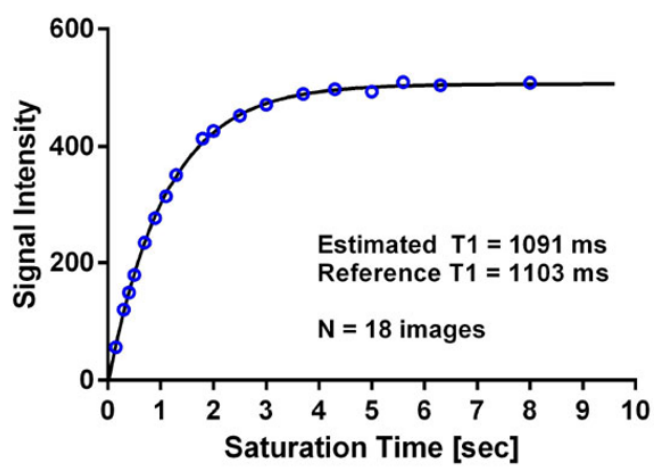

T2-Prepared bSSFP example fit

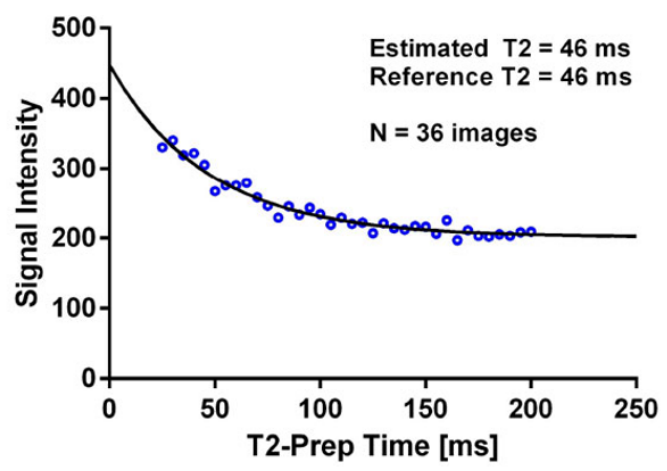

T1-MOLLI 5(3b)3 example fit

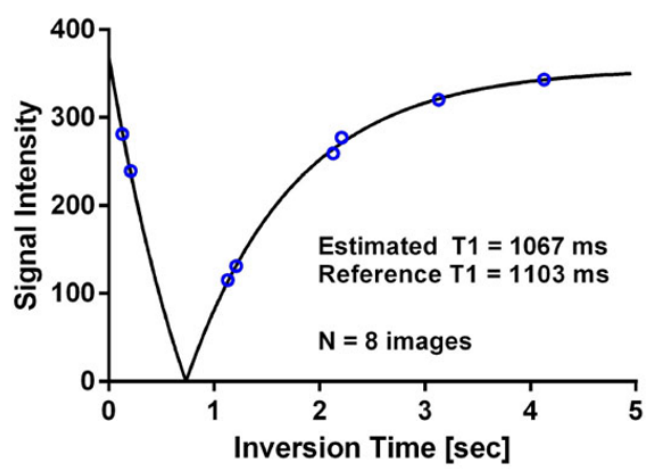

Figure 1 The left panel shows modified Bland-Altman analysis of the phantom validation and the right panel shows corresponding T1 \& T2 estimation examples from two phantoms. Left panel: Crosses indicate data-points, the solid lines indicate bias and the dotted lines correspond to bias +- 1.96 SD (Standard Deviation). Right panel: Solid lines represent estimated relaxation curves and blue circles indicate data-points. 
Table 1

\begin{tabular}{|c|c|c|}
\hline & Supported Signal models & \\
\hline Supported sequence-type & 3-parameter models & 2-parameter models \\
\hline T1 Inversion-Recovery (MAGIR) & $S(t)=|A(1-B \exp (-t / T 1))|$ & $S(t)=|A(1-2 \exp (-t / T 1))|$ \\
\hline T1 Phase-Sensitive Inversion-Recovery (PSIR) & $S(t)=A(1-B \exp (-t / T 1))$ & $S(t)=A(1-2 \exp (-t / T 1))$ \\
\hline T1 Saturation Recovery & $S(t)=A(1-B \exp (-t / T 1))$ & $S(t)=A(1-\exp (-t / T 1))$ \\
\hline T1 MOLLI/T1 Look-Locker MAG-images & $\begin{array}{c}S(t)=\left|A\left(1-B \exp \left(-t / T 1^{*}\right)\right)\right| \\
T 1=T 1^{*}(B-1)\end{array}$ & not available \\
\hline T1 MOLLI/T1 Look-Locker PSIR-images & $\begin{array}{c}\mathrm{S}(\mathrm{t})=\mathrm{A}\left(1-\mathrm{B} \exp \left(-\mathrm{t} / \mathrm{T} 1^{*}\right)\right) \\
\mathrm{T} 1=\mathrm{T} 1^{*}(\mathrm{~B}-1)\end{array}$ & not available \\
\hline T2 Spin-Echo (Multi-Echo or Single-Echo) & $\begin{array}{c}S(t)=A \exp (-t / T 2)+B ; \\
B>0\end{array}$ & $S(t)=A \exp (-t / T 2)$ \\
\hline T2-prepared bSSFP & $\begin{array}{c}S(t)=A \exp (-t / T 2)+B ; \\
B>0\end{array}$ & $S(t)=A \exp (-t / T 2)$ \\
\hline
\end{tabular}

Supported sequence types and signal models.

\section{References}

1. Arheden, et al: Radiology 1999, 211.

2. Ugander, et al: JACC CVI 2012, 5.

3. Heiberg, et al: BMC Med Im 2010, 10.

4. Akçakaya, et al: Magn Reson Med 2015, 74.

doi:10.1186/1532-429X-18-S1-W28

Cite this article as: Bidhult et al:: Validation of a T1 and T2 mapping

software for quantitative MRI. Journal of Cardiovascular Magnetic

Resonance 2016 18(Suppl 1):W28.

Submit your next manuscript to BioMed Central and take full advantage of:

- Convenient online submission

- Thorough peer review

- No space constraints or color figure charges

- Immediate publication on acceptance

- Inclusion in PubMed, CAS, Scopus and Google Scholar

- Research which is freely available for redistribution

Submit your manuscript at www.biomedcentral.com/submit
C Biomed Central 